\title{
Hoarding disorder secondary to pituitary adenoma: a case study
}

\section{Acumulação compulsiva secundária a adenoma pituitário: estudo de caso}

Alisson Paulino Trevizol', Pedro Shiozawa', Rodrigo Menezes Machado², Rodrigo Lancelote Alberto², Carlos Fernando Ramos ${ }^{3}$, Quirino Cordeiro ${ }^{1}$

Forty-three-year-old female with hoarding disorder for one year. No other neuropsychiatric background was referred. No laboratory changes. MRI showed a solid-cystic expansive tumor of $65 \times 47 \times 41 \mathrm{~mm}$ with significant mass effect over adjacent structures. Patient went through neurosurgery but died at the second day of post-operatory. Surgical pathology showed a slow-growth non-secreting pituitary adenoma. Neuroimaging studies of patients with hoarding disorder have drawn attention to specific brain regions related to the symptoms, including anterior cingulate cortex, dorsolateral prefrontal cortex and orbitofrontal cortex ${ }^{1,2,3}$. These structures were compressed by the tumor in the present case and could hypothetically be related to clinical presentation.
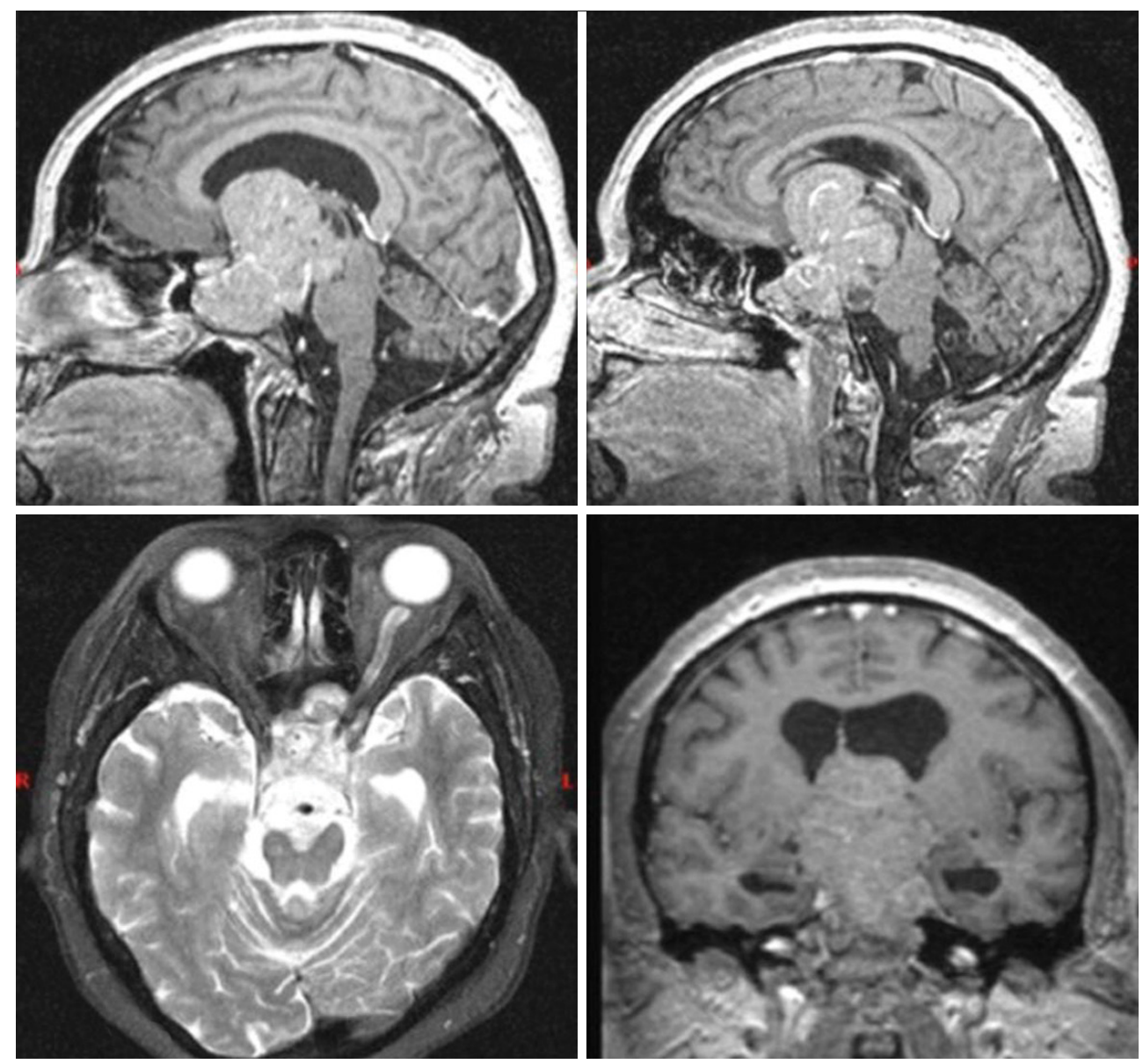

Figure. MRI showed a solid-cystic expansive tumor of $65 \times 47 \times 41 \mathrm{~mm}$ with significant mass effect over adjacent structures.

'Santa Casa de São Paulo, Faculdade de Ciências Médicas, Departamento de Psiquiatria, Laboratório de Neuromodulação Clínica, Sao Paulo SP, Brazil; ${ }^{2}$ Centro de Atenção Integrado à Saúde Mental de Franco da Rocha, Franco da Rocha SP, Brazil;

${ }^{3}$ Universidade Federal do ABC, Centro de Matemática, Computação e Cognição, Sao Bernardo do Campo SP, Brazil.

Correspondence: Pedro Shiozawa; Faculdade de Ciências Médicas da Santa Casa de São Paulo, Departamento de Psiquiatria; Rua Major Maragliano, 241 ;

04600-010 São Paulo SP, Brasil; E-mail: pedroshiozawa@gmail.com

Conflict of interest: There is no conflict of interest to declare.

Received 01 September 2015; Received in final form 17 December 2015; Accepted 05 Janurary 2016. 
1. Weitzner MA. Neuropsychiatry and pituitary disease: an overview. Psychother Psychosom. 1998;67(3):125-32. doi:10.1159/000012272

2. Mathews CA, Perez VB, Delucchi KL, Mathalon DH. Error-related negativity in individuals with obsessive-compulsive symptoms: toward an understanding of hoarding behaviors. Biol Psychol. 2012;89(2):487-94. doi:10.1016/j.biopsycho.2011.12.018

3. Weitzner MA, Kanfer S, Booth-Jones M. Apathy and pituitary disease: it has nothing to do with depression. J Neuropsychiatry Clin Neurosci. 2005;17(2):159-66. 